\title{
Formation of complex anodic films on porous alumina matrices
}

\author{
ALEXANDER ZAHARIEV and ASSEN GIRGINOV* \\ Department of Physical Chemistry, University of Chemical Technology and Metallurgy, 8 Kliment Ohridski blvd., \\ 1756 Sofia, Bulgaria
}

MS received 7 July 2002; revised 27 January 2003

\begin{abstract}
The kinetics of growth of complex anodic alumina films was investigated. These films were formed by filling porous oxide films (matrices) having deep pores. The porous films (matrices) were obtained voltastatically in $(\mathrm{COOH})_{2}$ aqueous solution under various voltages. The filling was done by re-anodization in an electrolyte solution not dissolving the film. Data about the kinetics of re-anodization depending on the porosity of the matrices were obtained. On the other hand, the slopes of the kinetic curves during reanodization were calculated by two equations expressing the dependence of these slopes on the ionic current density. A discrepancy was ascertained between the values of the calculated slopes and those experimentally found. For this discrepancy a possible explanation is proposed, related to the temperature increase in the film, because of that the real current density significantly increases during re-anodization.
\end{abstract}

Keywords. Complex anodic alumina films; re-anodization; pore filling.

\section{Introduction}

It is well known that during anodic polarization of aluminium in electrolyte solutions two types (Young 1961) of anodic oxide films can grow: barrier and porous. The barrier films are formed in electrolytes which do not dissolve the oxide film. They have a dense structure and follow the metal surface profile. The porous films are formed in electrolytes dissolving the oxide film and they have a double-layered structure (Wernick and Pinner 1972). The so-called barrier sub-layer grows at the metal/ oxide film interface. Above it a significantly thicker porous layer grows, whose pores are placed normally to the electrode surface. It is widely considered that the barrier sub-layer determines to a great extent the electric resistance of porous films.

A possibility exists to combine these two types of films by the manner described elsewhere (Dekker and van Geel 1947; Dekker and Middelhoek 1970; Takahashi and Nagayama 1978), viz. at first, formation of a porous film (matrix) in film-dissolving electrolyte takes place, followed by partial or complete filling of the matrix pores by re-anodization in non-dissolving electrolyte. As a result of this two-step anodization, the thickness of the barrier sub-layer increases. The new films obtained have been called complex films. These films have showed good dielectric properties (Wilson 1963; Tominaga et al 1968; Dickey et al 1989; Yakovleva et al 1998, 2000), high electric resistance (Yakovleva et al 1998) and high breakdown voltages (Machkova et al 1981, 1984). This is

\footnotetext{
*Author for correspondence
}

the reason for the increasing interest in their electrophysical properties as well as in the kinetics of their growth. The complex films can prove to be perspective dielectric materials for the capacitor production as well as for the needs of electrical engineering and electronics.

Data exists for the kinetics of filling both the porous matrices with shallow pores (Dekker and van Geel 1947; Girginov et al 2002a) and the matrices with deep pores (Dekker and van Geel 1947; Girginov et al 2002b). During the filling process, matrices having deep pores remain partially filled since the increase of the formation voltage is limited by electrical breakdowns (Machkova et al 1981, 1984). In this case the increase of the barrier sub-layer thickness at the oxide film/electrolyte interface takes place in the pores only, and the rate of increasing the voltage with time is very fast (Dekker and Middelhoek 1970). This is due to the fact that the real current density is significantly higher than the preset one, i.e. the process proceeds at comparatively high field strengths (Girginov et al 2002b).

The present work aims at investigating the kinetics of re-anodization of porous matrices having deep pores as a function of their porosity. For this purpose the conditions of a porous anodization were chosen according to the classic study of Keller et al (1953) on the structure of the porous alumina films.

\section{Theory} 2.1 Dependencies of the ionic current on the field
strength and temperature

It is known that the ionic current $\left(j_{i}\right)$ which ensures the growth of the barrier films depends on the field strength 
(E) and temperature $(T)$. This dependence has been investigated during anodization of different valve metals including Al (Andreeva and Ikonopisov 1970). The validity of two equations describing the $j_{\mathrm{i}}(E, T)$-dependence has been experimentally proven many times and theoretically interpreted (Christov and Ikonopisov 1969). (1) Günterschultze-Betz's equation:

$$
j_{\mathrm{i}}=A_{\mathrm{G}} \exp \left(-\frac{B_{\mathrm{G}}-\alpha_{\mathrm{G}} E}{k_{\mathrm{B}} T}\right) \text {, }
$$

where $A_{\mathrm{G}}, B_{\mathrm{G}}$ and $\alpha_{\mathrm{G}}$ are constants, which depend on the metal, but not on the electrolyte solution used, and $k_{\mathrm{B}}$ the Boltzmann's constant and (2) Young's (1963) equation:

$$
j_{\mathrm{i}}=A_{\mathrm{Y}} \exp \left(-\frac{B_{\mathrm{Y}}}{k_{\mathrm{B}} T}\right) \exp \left(\frac{\alpha_{\mathrm{Y}} E-\beta_{\mathrm{Y}} E^{2}}{k_{\mathrm{B}} T}\right),
$$

where $A_{\mathrm{Y}}, B_{\mathrm{Y}}, \alpha_{\mathrm{Y}}$ and $\beta_{\mathrm{Y}}$ are constants.

\subsection{Electric field strength during re-anodization}

The electric field strength in the anodic oxide can be determined via kinetic data, using Faraday's law:

$$
E=\frac{6 F \sigma \rho_{\mathrm{Al}_{2} \mathrm{O}_{3}}}{\lambda M_{\mathrm{Al}_{2} \mathrm{O}_{3}}}\left(\frac{\Delta U_{\mathrm{f}}}{\Delta Q_{\mathrm{f}}}\right)_{j, T},
$$

where $F$ is the Faraday's number, $\sigma$ the roughness factor (i.e. the ratio of the real to the geometrical surface), $\rho_{\mathrm{Al}_{2} \mathrm{O}_{3}}$ the density of the anodic oxide, $\lambda$ the current efficiency, $M_{\mathrm{Al}_{2} \mathrm{O}_{3}}$ the molar weight of the anodic $\mathrm{Al}_{2} \mathrm{O}_{3}$, respectively. $\left(\Delta U_{\mathrm{f}} / \Delta Q_{\mathrm{f}}\right)_{j, T}$ is the slope of the dependence of the voltage $\left(U_{\mathrm{f}}\right)$ on the charge density $\left(Q_{\mathrm{f}}\right)$ during re-anodization.

\section{Experimental}

Specimens of high purity aluminium foil $(99.99 \% \mathrm{Al})$ having a working area of $5 \mathrm{~cm}^{2}$ were used. They were consequently electropolished, brightened and rinsed by the usual manner before anodization. The porous anodic alumina films were formed in $2 \mathrm{wt} \%$ aqueous solution of $(\mathrm{COOH})_{2}$ at a constant voltage $\left(U_{\mathrm{V}}\right)$ and a constant temperature $\left(24 \pm 0 \cdot 1^{\circ} \mathrm{C}\right)$ for $5 \mathrm{~min}$. By varying $U_{\mathrm{V}}$ in the range from 5 to $80 \mathrm{~V}$ porous matrices with different thicknesses were obtained (Keller et al 1953). Filling of the porous matrices was carried out by re-anodization in an aqueous borate electrolyte (ABE). For this electrolyte solution (2.5 wt.\% $\quad \mathrm{H}_{3} \mathrm{BO}_{3}$ neutralized by $\mathrm{NH}_{4} \mathrm{OH}$ to $\mathrm{pH}=6$ ), it is known that it does not dissolve the oxide film (Andreeva and Ikonopisov 1970). The filling was carried out galvanostatically $\left(10^{-3} \mathrm{~A} \mathrm{~cm}^{-2}\right)$ at a constant temperature $\left(20 \pm 0 \cdot 1^{\circ} \mathrm{C}\right)$. The re-anodization was interrupted always at one and the same re-anodization voltage $\left(U_{\mathrm{f}}=400 \mathrm{~V}\right)$. This value was chosen to be lower than the voltages at which electrical breakdowns occur. Under these conditions the barrier sub-layer had a thickness of $500 \mathrm{~nm}$. A two-electrode cell consisting of a specimen as a working electrode and a Pt grid as a counter electrode was used. The re-anodization voltage $\left(U_{\mathrm{f}}\right)$ was recorded by $Y-t$ recorder (MSW Endim 621.01, Germany).

\section{Results and discussion}

The porous matrices formed under the conditions described above have deep $\left(5 \times 10^{-4} \div 20 \times 10^{-4} \mathrm{~cm}\right)$ and narrow pores (diameter $1.2 \times 10^{-6} \mathrm{~cm}$ ) as it is schematically shown in figure 1a. It is known that when these matrices undergo re-anodization they are being filled up always only partially (Girginov et al 2002b) since breakdowns

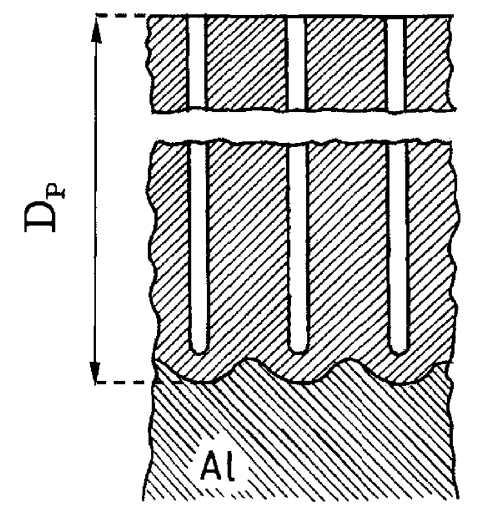

(a)

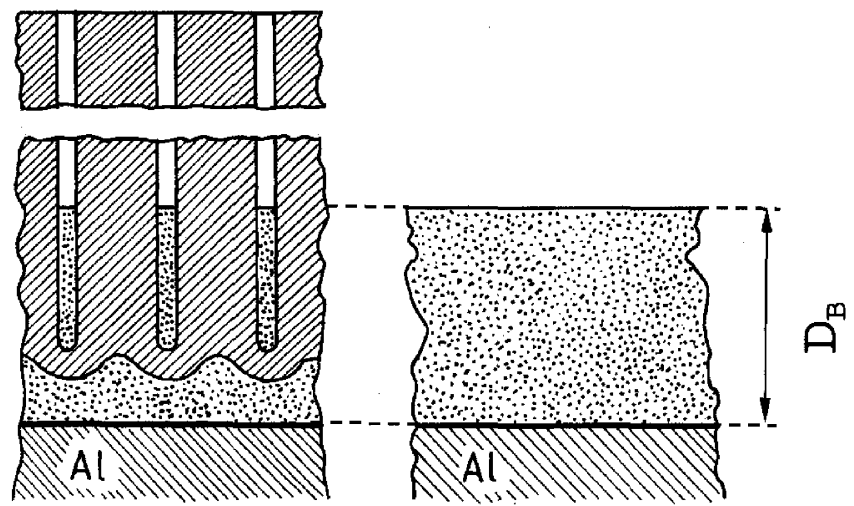

(b) (c)

Figure 1. Schematic presentation of the structure of anodic films on $\mathrm{Al}$ : (a) porous film with deep pores; (b) complex film obtained after filling porous matrix with deep pores and (c) barrier-type anodic film. 
occur (figure 1b). The obtained porous matrices were filled up by secondary anodization in ABE. During the process of re-anodization a dependence of re-anodization voltage $\left(U_{\mathrm{f}}\right)$ vs time (the electrical charge density $\left(Q_{\mathrm{f}}\right)$ passed, respectively) was recorded. A typical kinetic $U_{\mathrm{f}}\left(Q_{\mathrm{f}}\right)$-curve of re-anodization is presented in figure 2 . In the same figure, a kinetic curve of direct barrier anodization of $\mathrm{Al}$ in the same electrolyte (ABE) is shown. By comparing both the curves, well known facts are ascertained: the breakdown voltage during re-anodization is higher (Machkova et al 1981, 1984) and the rate of increase in $U_{\mathrm{f}}$ vs $Q_{\mathrm{f}}$ is faster (Girginov et al 2002a,b). All porous matrices were filled up to one and the same voltage $\left(U_{\mathrm{f}}=400 \mathrm{~V}\right)$ in order to finish the re-anodization just before reaching the breakdown voltage.

From the kinetic curves the slopes $\left(\mathrm{d} U_{\mathrm{f}} / \mathrm{d} Q_{\mathrm{f}}\right)$ of re-anodization were determined. The slopes for filling porous matrices, obtained at different formation voltages $\left(U_{\mathrm{V}}\right)$ of a voltastatic porous anodization are presented in figure 3 . From this figure it is seen that the values of the slopes

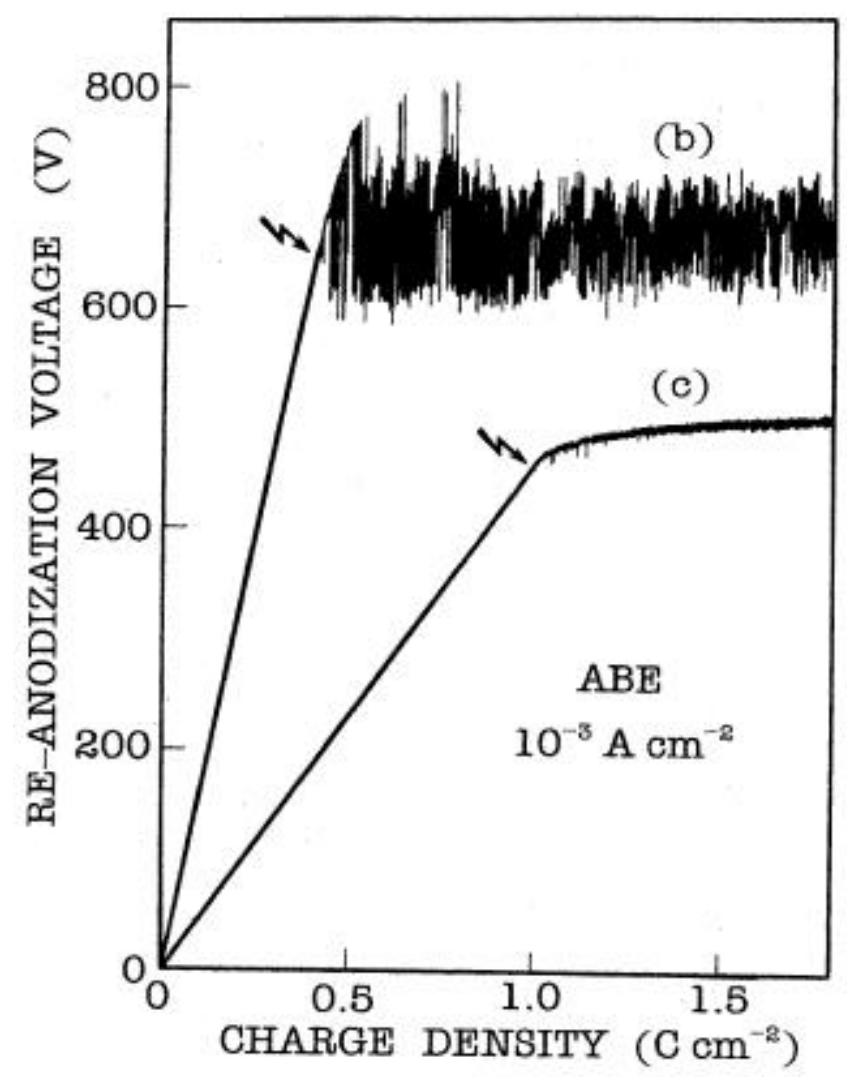

Figure 2. Dependence of the re-anodization voltage on the charge density passed during the filling of porous film with deep pores (see figure 1a). The re-anodization results in a complex film with partially filled pores (b). The porous film was grown at $U_{\mathrm{V}}=80 \mathrm{~V}$ and during $0.3 \mathrm{ks}$ of anodization. For comparison, a kinetic curve of direct barrier anodization of $\mathrm{Al}$ in $\mathrm{ABE}$ is shown in (c). The first spark voltage is indicated by broken arrows. $\left(\mathrm{d} U_{\mathrm{f}} / \mathrm{d} Q_{\mathrm{f}}\right)$ of the kinetic curves generally increase with increasing $U_{\mathrm{V}}$.

In the classic investigations of Keller et al (1953) on the structure of the porous anodic alumina films it is found that the porosity $(\alpha)$, i.e. the ratio of the pores section $\left(S_{\text {pore }}\right)$ to the entire electrode surface $\left(S_{\text {total }}\right)$, depends on the values of the voltages at which the porous films are formed. This is found not only for the films formed in $(\mathrm{COOH})_{2}$ solution, but for films formed also in the other film-dissolving electrolytes $\left(\mathrm{H}_{2} \mathrm{SO}_{4}, \mathrm{H}_{2} \mathrm{CrO}_{4}, \mathrm{H}_{3} \mathrm{PO}_{4}\right)$. Similar results have been derived by other authors (Dekker and Middelhoek 1970). The dependence of the porosity on the porous anodization voltage according to Keller et al (1953) is presented in figure 4.

During filling the porous matrices the current flows preferably through the bottom of the pores (i.e. through the barrier sub-layer) and the real current density is significantly greater than the preset one. As it has been mentioned above, the re-anodization was carried out always at one and the same current density $\left(10^{-3} \mathrm{~A} \mathrm{~cm}^{-2}\right)$. Considering the data from figure 4 , the real current density (the one passing through the pores) vs voltage, $U_{\mathrm{V}}$ (at which the porous films were obtained), can be determined. This dependence is presented in figure 5 . From this figure it is clearly seen that the real current density changes itself more than ten-fold in comparison to the preset current density.

A possibility exists based on (1) and (2) for the field and temperature dependence of ionic current, and consi-

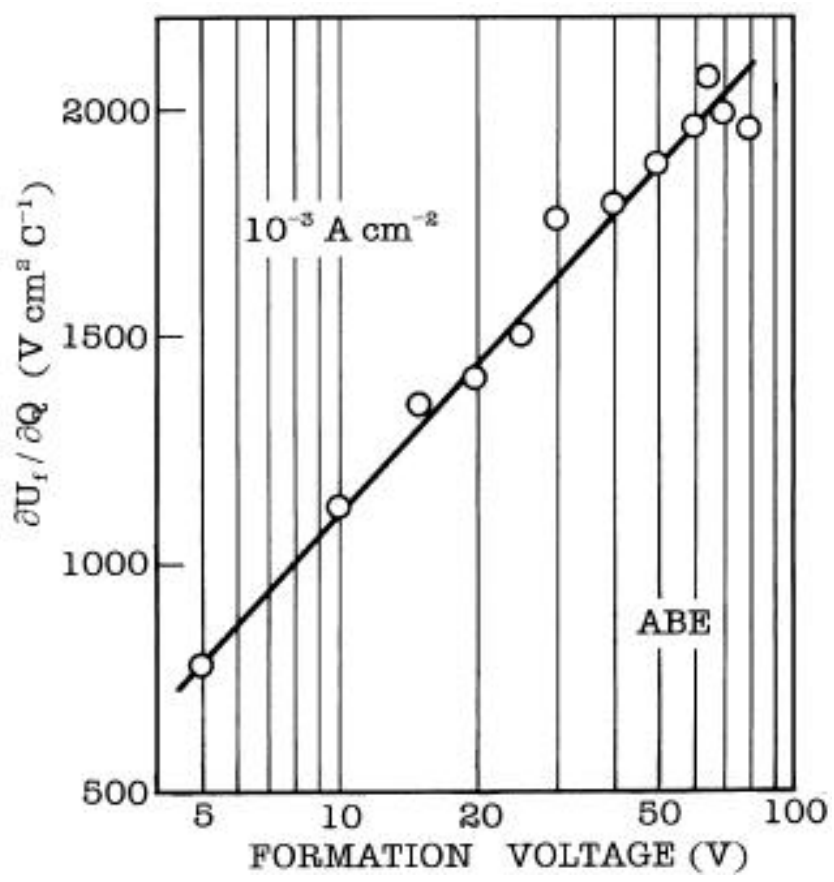

Figure 3. Dependence of the slopes of the kinetic curves of re-anodization in $\mathrm{ABE}$ on the voltage, $U_{\mathrm{V}}$, for formation of porous films. The filling was carried out galvanostatically $\left(10^{-3} \mathrm{~A} \mathrm{~cm}^{-2}\right)$. 
dering (3), to obtain expressions for the slopes of the re-anodization kinetic curves and to compare the calculated slopes to those experimentally found.

By combining (1) and (3), the following expression is obtained:

$$
\left(\frac{\Delta U_{\mathrm{f}}}{\Delta Q_{\mathrm{f}}}\right)_{j, T}=\frac{\lambda M_{\mathrm{Al}_{2} \mathrm{O}_{3}}}{6 F \sigma \rho_{\mathrm{Al}_{2} \mathrm{O}_{3}}}\left[\frac{k_{\mathrm{B}} T \ln \left(j_{\mathrm{i}} / A_{\mathrm{G}}\right)+B_{\mathrm{G}}}{\alpha_{\mathrm{G}}}\right] .
$$

The values of the constants, $A_{\mathrm{G}}=1.644 \times 10^{10} \mathrm{~A} \mathrm{~cm}^{-2}$, $B_{\mathrm{G}}=1.495 \mathrm{eV}$ and $\alpha_{\mathrm{G}}=9 \times 10^{-8} \mathrm{e} \mathrm{cm}$, have been calculated by Andreeva and Ikonopisov (1970) for anodization of $\mathrm{Al}$ in $\mathrm{ABE}$. The Boltzmann's constant has been expressed as $k_{\mathrm{B}}=8.61 \times 10^{-5} \mathrm{eV} \mathrm{K}^{-1}$.

By analogy, the combined solution of (2) and (3) leads to the equation

$$
\begin{aligned}
& \left(\frac{\Delta U_{\mathrm{f}}}{\Delta Q_{\mathrm{f}}}\right)_{j, T}=\frac{\lambda M_{\mathrm{Al}_{2} \mathrm{O}_{3}}}{6 F \sigma \rho_{\mathrm{Al}_{2} \mathrm{O}_{3}}} \\
& {\left[\frac{\alpha_{\mathrm{Y}}}{2 \beta_{\mathrm{Y}}}-\sqrt{\frac{\left(\alpha_{\mathrm{Y}}^{2} / 4 \beta_{\mathrm{Y}}\right)-k_{\mathrm{B}} T \ln \left(j_{\mathrm{i}} / A_{\mathrm{Y}}\right)-B_{\mathrm{Y}}}{\alpha_{\mathrm{Y}}}}\right] .}
\end{aligned}
$$

The constants, $A_{\mathrm{Y}}=1.164 \times 10^{10} \mathrm{~A} \mathrm{~cm}^{-2}, \quad B_{\mathrm{Y}}=1.95$ $\mathrm{eV}, \alpha_{\mathrm{Y}}=2.126 \times 10^{-7} \mathrm{e} \mathrm{cm}$ and $\beta_{\mathrm{Y}}=8.027 \times 10^{-15} \mathrm{e} \mathrm{cm}^{2} \mathrm{~V}^{-1}$,

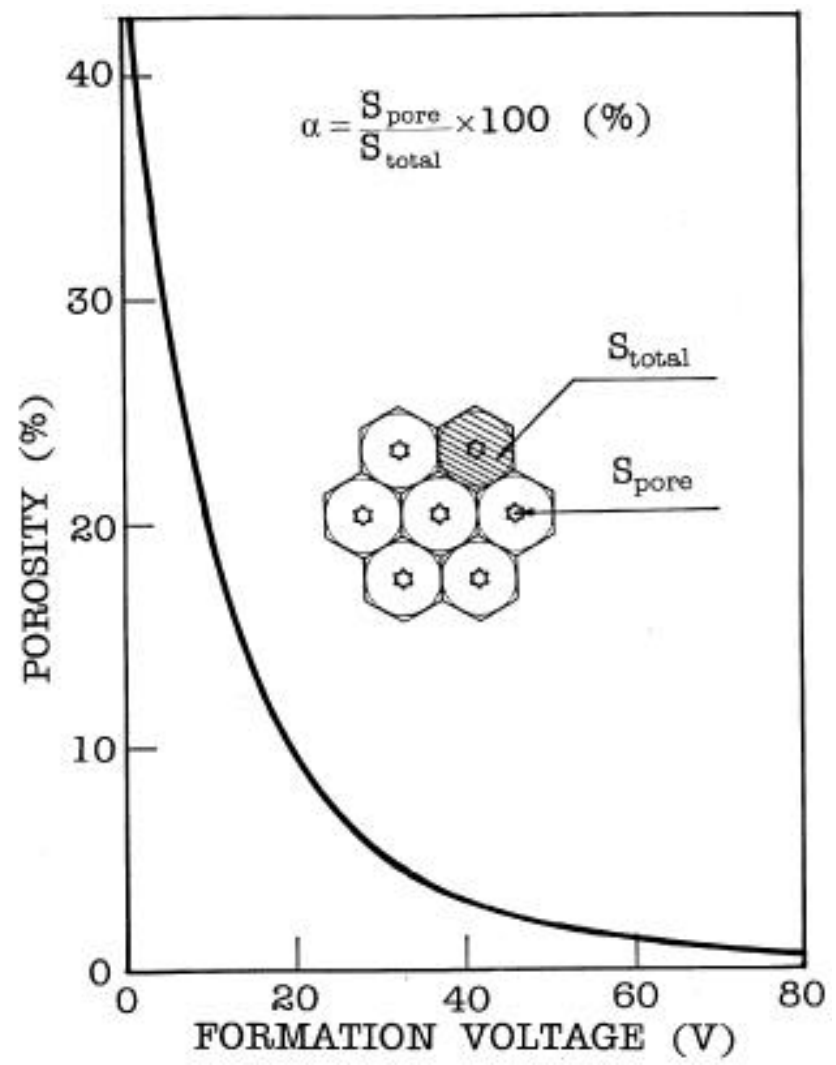

Figure 4. Dependence of the porosity of the porous matrices on the voltage, $U_{\mathrm{V}}$, of a voltastatic anodization in $(\mathrm{COOH})_{2}$ solution. have also been determined for anodization of $\mathrm{Al}$ in $\mathrm{ABE}$ (Andreeva and Ikonopisov 1970).

Calculating the slopes of the kinetic curves by (4) and (5), for $j_{\mathrm{i}}$ the values of the real current density were used $\left(j_{\text {real }}=j_{\text {total }} / \alpha\right)$. The real current densities were derived according to the data from figure 5 for the relevant voltages of voltastatic anodization. The values for $\rho_{\mathrm{Al}_{2} \mathrm{O}_{3}}=$ $3 \cdot 145 \mathrm{~g} \mathrm{~cm}^{-3}$ (Ikonopisov et al 1969) and for $M_{\mathrm{Al}_{2} \mathrm{O}_{3}}=102$ $\mathrm{g} \mathrm{mol}^{-1}$ were used. The current efficiency $(\lambda)$ was accepted to be equal to 1 , because it has been proved (Ikonopisov and Andreeva 1969) that the barrier anodization of $\mathrm{Al}$ in ABE occurs with $100 \%$ efficiency. The calculations were also carried out assuming the roughness factor $(\sigma)$ to be unity. The calculated values of the slopes using (4) and (5) were compared with those experimentally found (figure 6).

It is seen from figure 6 that the slopes $\left(\Delta U_{\mathrm{f}} / \Delta Q_{\mathrm{f}}\right)_{j, T}$ calculated by (4) and (5) are significantly lower than those experimentally found.

A possible explanation for this discrepancy can be proposed: this is probably due to the fact that the constants in (1) and (2) have been determined experimentally in a comparatively small range of current densities $\left(j_{i}=\right.$ $\left.10^{-5} \div 5 \times 10^{-3} \mathrm{~A} \mathrm{~cm}^{-2}\right)$, electrical field strengths $(E=6 \cdot 5$ $\left.\times 10^{6} \div 9 \times 10^{6} \mathrm{~V} \mathrm{~cm}^{-1}\right)$ and temperatures $(274 \div 313 \mathrm{~K})$, respectively. Obviously, an extrapolation far beyond the experimental data at high current densities (field strengths, respectively) seems to be not very reliable. Moreover, during anodization of aluminium in $\mathrm{ABE}$ at higher current densities a great increase of the effective tempe-

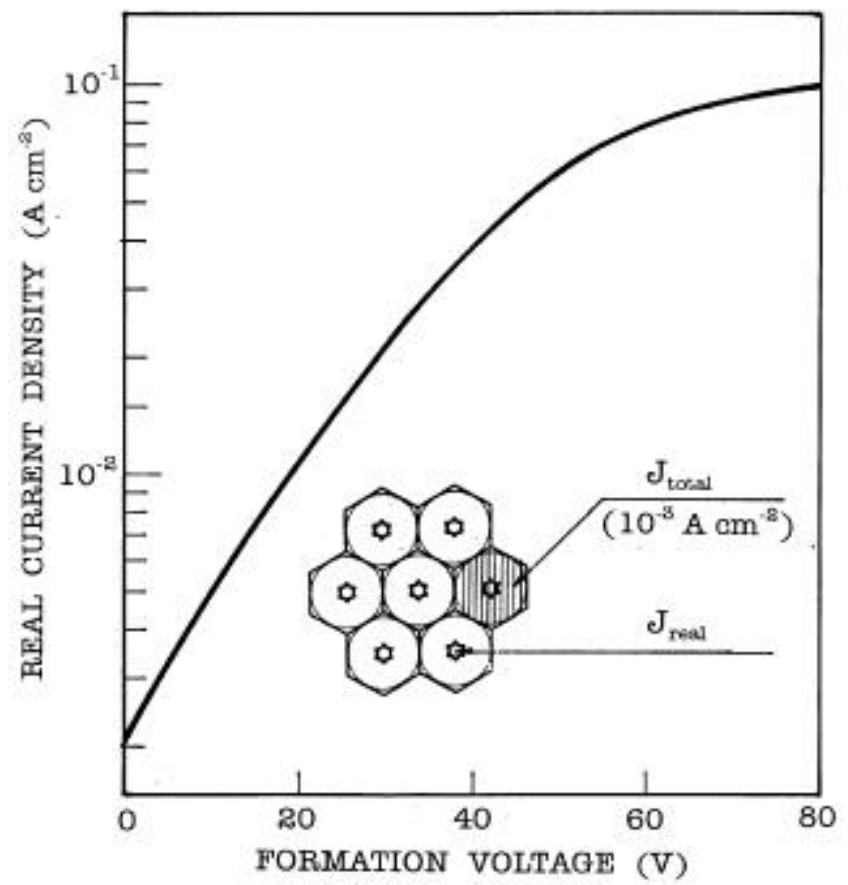

Figure 5. Real current density during filling of porous matrices with deep pores vs the voltage, $U_{\mathrm{v}}$, of the porous anodization. 


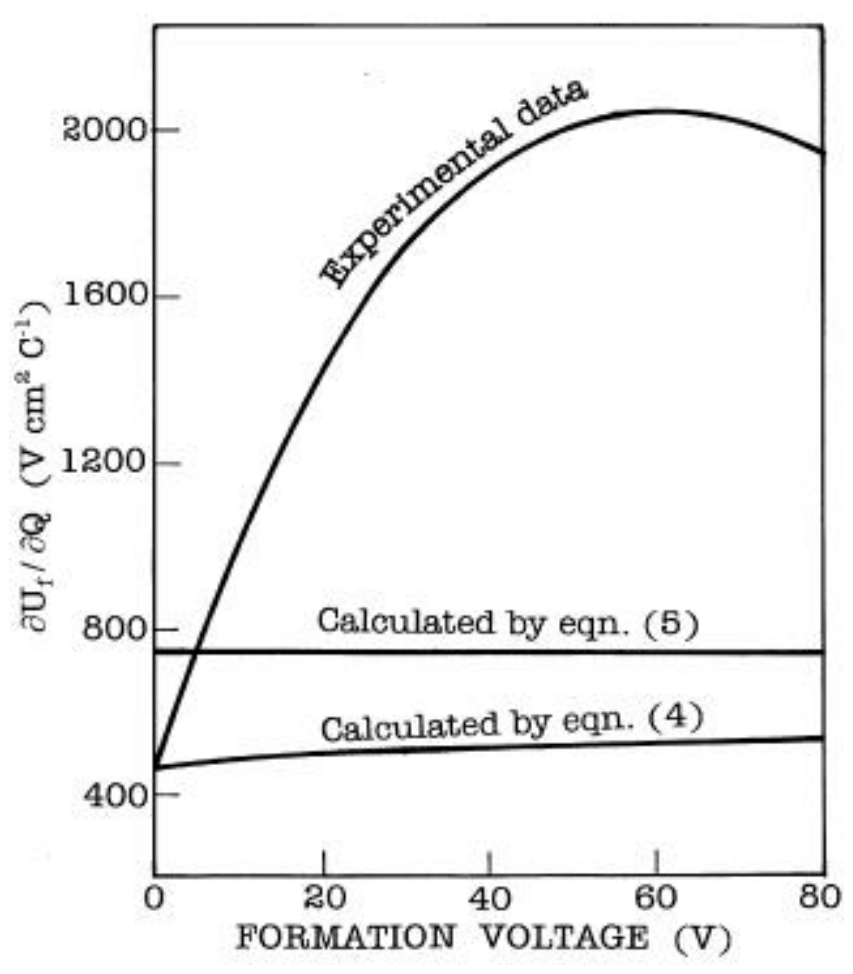

Figure 6. Comparison of the experimental data and those calculated by (4) and (5) for the dependence of the kinetic slopes vs the voltage, $U_{\mathrm{V}}$, of porous anodization.

rature (Ikonopisov and Andreeva 1970) in the film of about several hundred degrees is proposed. This temperature increase will lead to the increase of the values of $\left(\Delta U_{\mathrm{f}} / \Delta Q_{\mathrm{f}}\right)_{j, T}$ according to (4) and (5).

\section{Conclusions}

By re-anodization of porous anodic oxide films on aluminium grown in $(\mathrm{COOH})_{2}$, in an aqueous borate electrolyte, complex anodic alumina films could be successfully formed. A strong dependence of the kinetics of re-anodization on the formation voltage at which the porous matrices were formed (on their porosity, respectively), was observed. A great deviation of the experimentally derived slopes of the re-anodization curves in comparison with calculated slopes was found. It was proved that the available values of the constants in the dependences of the ionic current on electric field strength and temperature are inapplicable during anodization (re-anodization, respectively) at high current densities. A possible explanation of this deviation was given in view of the temperature increase in the film during the re-anodization of the porous matrices. The kinetic data obtained could be useful in obtaining complex films with certain structure and functional properties.

\section{References}

Andreeva L and Ikonopisov S 1970 Elektrokhimiya 61070

Christov S G and Ikonopisov S 1969 J. Electrochem. Soc. 116 56

Dekker A J and van Geel W Ch 1947 Philips. Res. Rep. 2313

Dekker A and Middelhoek A 1970 J. Electrochem. Soc. 117 440

Dickey J R, Davidson J L and Tzeng Y 1989 J. Electrochem. Soc. 1361772

Girginov A, Zahariev A and Machkova M 2002a J. Univ. Chem. Tech. Met. XXXVII 11

Girginov A, Zahariev A and Machkova M 2002b Mater. Chem. Phys. 76274

Ikonopisov S and Andreeva L 1969 Elektrokhimiya 51358

Ikonopisov S and Andreeva L 1970 Elektrokhimiya 61412

Ikonopisov S, Andreeva L and Vodenicharov C 1969 Electrochim. Acta 15421

Keller F, Hunter M S and Robinson D L 1953 J. Electrochem. Soc. $\mathbf{1 0 0} 411$

Machkova M, Girginov A, Klein E and Ikonopisov S 1981 Surf. Technol. 14241

Machkova M, Klein E, Girginov A and Ikonopisov S 1984 Surf. Technol. 2221

Takahashi H and Nagayama M 1978 Corr. Sci. 18911

Tominaga H, Hiyama S and Sasaki H 1968 Fujitsu Sci. Tech. J. 4183

Wernick S and Pinner R 1972 The surface treatment and finishing of aluminium and its alloys (Teddington, UK: Robert Draper Ltd.) 4th ed. p. 319

Wilson R F 1963 Wireless World 146

Yakovleva N M, Yakovlev A N and Chupahina E A 1998 Inorg. Mater. 34855

Yakovleva N M, Yakovlev A N and Chupahina E A 2000 Thin Solid Films 36637

Young L 1961 Anodic oxide films (London and New York: Academic Press) p. 285

Young L 1963 J. Electrochem. Soc. 110598 